Research Article

\title{
A Descriptive Study to Assess the Knowledge and Practice on Personal Protective Equipment among Student Nurses in a Selected College of Nursing, New Delhi
}

\author{
Gifty Bijoy', Uzma Anjum ${ }^{2}$ \\ 1,2Tutor, Rufaida College of Nursing, Jamia Hamdard, New Delhi, India. \\ DOI: https://doi.org/10.24321/2455.9318.202028
}

\section{I $\quad \mathbf{N} \quad \mathbf{F} \quad \mathbf{O}$}

\section{Corresponding Author:}

Uzma Anjum, College of Nursing, Jamia Hamdard, New Delhi, India.

E-mail Id:

uzma.jh@gmail.com

Orcid Id:

https://orcid.org/0000-0002-2540-5130

How to cite this article:

Bijoy G, Anjum U. A Descriptive Study to Assess the Knowledge and Practice on Personal Protective Equipment among Student Nurses in a Selected College of Nursing, New Delhi. Int J Nurs Midwif Res 2020; 7(4): 8-12.

Date of Submission: 2020-12-04

Date of Acceptance: 2020-12-20

\section{$\begin{array}{llllllllllll}\mathbf{A} & \mathbf{B} & \mathbf{S} & \mathbf{T} & \mathbf{R} & \mathbf{A} & \mathbf{C} & \mathbf{T}\end{array}$}

Personal Protective equipment is also called PPE. It is commonly worn by health care workers to prevent the transmission of infection. PPE includes helmets or caps, face shields, face masks, goggles, gowns, respirators, shoe covers or boots and gloves. These protective coverings will be effective when it is being used in an appropriate manner. The main objectives of this study were to assess the knowledge and practice on Personal Protective Equipment among student nurses. A Quantitative Research approach along with Descriptive Research design was used. A total of 110 student nurses were selected through Convenient Sampling Technique from DGNM $3^{\text {rd }}$ Year, B.Sc. (Hons.) Nursing $2^{\text {nd }}$ Year and B.Sc. (Hons.) Nursing $4^{\text {th }}$ Year of Rufaida College of Nursing, Jamia Hamdard, New Delhi in the month of July-August 2020. Structured Questionnaire was used via an online platform (Google forms) due to Covid 19 lockdown to assess the knowledge and practice on PPE. Out of 110 samples, $66(60 \%)$ had good knowledge, followed by $44(40 \%)$ having average knowledge and none were having poor knowledge on PPE, whereas 67 (60.9\%) had an average practice, followed by 41 (37.3\%) having good practice and only $2(1.8 \%)$ had poor practice on PPE. Findings suggest that there is a need for practice-based knowledge assessment in clinical areas and thus improvement in the practice of PPE while working in hospitals.

Keywords: Personal Protective Equipment (PPE), Knowledge, Practice

\section{Introduction}

PPE helps prevent high-risk patients from contracting infections after being exposed to substances or potentially infectious material brought in by visitors and healthcare workers. When used correctly together with other infection control practices such as hand-washing, use of alcohol- based hand sanitisers, covering the face while coughing and sneezing, it minimizes the spread of infection from one person to another. Effective use of PPE also includes the proper removal and disposal of contaminated PPE to prevent exposure to infections for both: The PPE wearer and other people. ${ }^{1}$ 
When a pathogenic organism enters into the person body it causes the infection by multiplication and affects the host. By this invasion of an organism into the body's tissue and multiplication, it starts the changes inside the body's tissue. This response of an organism cause symptoms in the host and the host become ill. These types of infectious diseases also called communicable diseases. ${ }^{2}$ Health careassociated infection (HCAl), also referred to as "nosocomial" or "hospital-acquired" infection, is an infection occurring in a patient during the process of care in a hospital or other health care facility which was not present or incubating at the time of admission. HCAl can affect patients in any type of setting where they receive care and can also appear after discharge. $^{3}$

Nosocomial infections transmitted by direct contact can be prevented by adapting standard precautions guidelines. Appropriate use of PPE is the easiest way to prevent contact from secretions and the transfer of pathogens. It's important to assess the level of compliance with the use of PPE by the various HCWs who make direct contact with patients. ${ }^{4}$

There weren't any rules for the protection of health care personnel until the introduction of Occupational Safety and Health Act of 1970. It was brought to protect health care worker's safety and prevent injuries due to occupational hazards. It covered both private and government sector workers ensuring their safety and was considered by the people as a great effort in terms of public priority, concern and safety. ${ }^{5}$

It was observed that the student Nurses who only have acquired knowledge of PPE usage have insufficient practical awareness, skills and expertise to apply during their clinical routines thereby greatly reducing the effectiveness of PPE making themselves and the patients vulnerable for infection and $/$ or becoming the carriers of infection. It is therefore recommended that their education and training must impart these skills thoroughly as they graduate out of college.

\section{Aims}

Through an extensive review of existing literature, the researcher felt the need to explore the knowledge and practice of PPE amongst student nurses. So, the present study was conducted with the following objectives:

- To assess the knowledge on PPE among student nurses

- To assess the practice on PPE among student nurses

\section{Materials and Methods}

Quantitative approach with descriptive research design was used for the study. Structured knowledge and practice questionnaires were designed to collect the data regarding the knowledge and practice related to PPE usage. This study was conducted in Nursing college and the students of 3 batches were taken as samples from $30^{\text {th }}$ July to $18^{\text {th }}$
August 2020 at Rufaida College of Nursing. 110 students (B.Sc. Hons. Nursing II year IV year and DGNM III year) were selected using Convenient Sampling Technique via online forms (Google forms). Attrition and sample contamination were prevented during the data collection. The tool for data collection comprised of three sections: Section 1 includes demographic characteristics of the subject and Section 2 consisting of a structured questionnaire to assess the Knowledge and Section 3 consisting of a structured questionnaire to assess the Practice regarding PPE. This was developed with 9 demographic related items and along with 20 items related to knowledge respectively and 14 items related to practice of PPE. The tools were developed after extensive review by 8 experts from the field of Nursing. Scoring was done by dividing the scores into different categories as reflected in Table 1(a) and Table 1(b).

Table I(a).Categories of Knowledge Score

\begin{tabular}{|c|c|}
\hline Category & Score \\
\hline Poor & $0-6$ \\
\hline Average & $7-13$ \\
\hline Good & $14-20$ \\
\hline
\end{tabular}

Table I(b).Categories of Practice Score

\begin{tabular}{|c|c|}
\hline Category & Score \\
\hline Poor & $0-4$ \\
\hline Average & $5-9$ \\
\hline Good & $10-14$ \\
\hline
\end{tabular}

Consent had been obtained prior to the participation of participants and adequate levels of confidentiality and anonymity of students for the research data was ensured. The tools were administered on the selected sample. Data were analysed using descriptive statistics.

\section{Results}

The results are discussed under the following sections:

\section{Findings Related to Demographic Characteristics}

Table 2 depicts that more than half of the samples 58 (53\%) belonged to the age group of 20-21 years, majority of the samples $88(80 \%)$ were females, whereas, $45(41 \%)$ were from B.Sc. H. Nursing II Year, 64 (58\%) of the sample's father were working in Non- Medical Field whereas most of the sample's mothers 71 (65\%) were unemployed.

Majority of samples 87 (79\%) resided in urban areas. Most of the student nurses 60 (55\%) acquired knowledge regarding PPE from clinical teaching, majority of the samples 94 (85\%) had clinical exposure to HAHC Hospital and Safdarjung Hospital, most of the student nurses $75(68 \%)$ had attended a workshop or training programme on PPE. 
Table 2.Frequency and Distribution of the Study Subjects According to their Various Demographic Characteristics

\begin{tabular}{|c|c|c|c|}
\hline S. No. & Demographic Profile & Frequency (f) & Percentage (\%) \\
\hline \multirow{5}{*}{1.} & \multicolumn{3}{|c|}{ Age (in years) } \\
\hline & $18-19$ & 4 & 4 \\
\hline & $20-21$ & 58 & 53 \\
\hline & $22-23$ & 39 & 35 \\
\hline & 24 and above & 9 & 8 \\
\hline \multirow{3}{*}{2.} & \multicolumn{3}{|c|}{ Gender } \\
\hline & Male & 22 & 20 \\
\hline & Female & 88 & 80 \\
\hline \multirow{4}{*}{3.} & \multicolumn{3}{|c|}{ Education } \\
\hline & GNM III Year & 29 & 26 \\
\hline & B.Sc. H. Nursing, II Year & 45 & 41 \\
\hline & B.Sc. H. Nursing, IV Year & 36 & 33 \\
\hline \multirow{5}{*}{4.} & \multicolumn{3}{|c|}{ Father's occupation } \\
\hline & Medical & 17 & 15 \\
\hline & Non- Medical & 64 & 58 \\
\hline & Unemployed & 16 & 15 \\
\hline & Entrepreneur & 13 & 12 \\
\hline \multirow{5}{*}{5.} & \multicolumn{3}{|c|}{ Mother's occupation } \\
\hline & Medical & 8 & 7 \\
\hline & Non- Medical & 26 & 24 \\
\hline & Unemployed & 71 & 65 \\
\hline & Entrepreneur & 5 & 4 \\
\hline \multirow{3}{*}{6.} & \multicolumn{3}{|c|}{ Area of residence } \\
\hline & Rural area & 23 & 21 \\
\hline & Urban area & 87 & 79 \\
\hline \multirow{5}{*}{7.} & \multicolumn{3}{|c|}{ Source of information regarding PPE } \\
\hline & Classroom Teaching & 36 & 33 \\
\hline & Clinical Teaching & 60 & 55 \\
\hline & Books/magazines/ newspapers & 11 & 10 \\
\hline & All of the above & 3 & 2 \\
\hline \multirow{4}{*}{8.} & \multicolumn{3}{|c|}{ Previous clinical exposure in hospital } \\
\hline & HAHC Hospital & 1 & 1 \\
\hline & Safdarjung Hospital & 15 & 14 \\
\hline & Both & 94 & 85 \\
\hline \multirow{3}{*}{9.} & \multicolumn{3}{|c|}{ Attended a workshop or training program on PPE } \\
\hline & Yes & 75 & 68 \\
\hline & No & 35 & 32 \\
\hline
\end{tabular}


Table 3(a).Frequency and Percentage Distribution of Knowledge on PPE

\begin{tabular}{|c|c|c|}
\hline Knowledge Score & Frequency & Percentage (\%) \\
\hline Poor $(<6)$ & 0 & 0 \\
\hline Average $(7-13)$ & 44 & 40 \\
\hline Good (14-20) & 66 & 60 \\
\hline
\end{tabular}

Table 3(b). Mean, Median, Mode and Standard Deviation of knowledge on PPE

$(\mathrm{N}=110)$

\begin{tabular}{|c|c|c|c|c|c|c|}
\hline Variable & Possible range of score & Obtained range of score & Mean & Median & Mode & Standard Deviation \\
\hline $\begin{array}{c}\text { Knowledge } \\
\text { Score }\end{array}$ & $0-20$ & $7-19$ & 12.827 & 13 & 13 & 2.4452 \\
\hline
\end{tabular}

Table 4(a).Frequency and Percentage Distribution of Practice of Students on PPE

$(\mathrm{N}=110)$

\begin{tabular}{|c|c|c|}
\hline Practice Score & Frequency & Percentage (\%) \\
\hline Poor (<4) & 2 & 60.9 \\
\hline Average (5-9) & 67 & 37.3 \\
\hline Good (10-14) & 41 & 2.8 \\
\hline
\end{tabular}

Table 4(b). Mean, Median, Mode and Standard Deviation of Practice of Students on PPE

$(\mathrm{N}=110$

\begin{tabular}{|c|c|c|c|c|c|c|}
\hline Variable & Possible range of score & Obtained range of score & Mean & Median & Mode & Standard Deviation \\
\hline Practice Score & $0-14$ & $4-14$ & 8.74 & 9 & 9 & 1.98 \\
\hline
\end{tabular}

\section{Findings Related to the Knowledge on PPE}

The data presented in Table 3(a) highlights the knowledge on PPE amongst student nurses. Majority of samples i.e., $66(60 \%)$ had good knowledge and $44(40 \%)$ had average knowledge on PPE.

As shown in Table 3(b), the Mean of the obtained range of score was 12.827, the Median was 13, the Mode was 13 and the Standard Deviation was 2.4452.

\section{Findings Related to the Practice on PPE}

The data presented in Table 4(a), shows the practice of PPE among student nurses. Majority of samples i.e., 67 (60.9\%) had an average practice on PPE, followed by 41 (37.3\%) having good practice on PPE and only 2 (1.8\%) had poor practice on PPE.

As shown in Table 4(b), the Mean of the obtained range of score was 8.74, the Median was 9, the Mode was 9 and the Standard Deviation was 1.98.

\section{Discussion}

The findings of the study show that in the assessment of knowledge on PPE, majority of student nurses i.e., out of 110 samples, 66 (60\%) had good knowledge score but when it came to the assessment of practice on PPE, maximum of samples i.e., 67 (60.9\%) had an average practice score. This result indicates that although the samples have good knowledge on PPE, they lack in following the standard practice in the clinical setting. This difference in knowledge and practice of PPE affects the health of both Health Care Workers and the patients. The improper practise of PPE is the cause of spread infections and other injuries.

A similar study was conducted by Archana Lakshmi PA, on personal protective equipment use among health care providers. A cross-sectional study was conducted from November 2014 to October 2015 in two tertiary health care institutions in Tamil Nadu, to evaluate the appropriate use of PPE among health care providers. Total participants were 1060, health care providers i.e., Doctors, nurses and technicians who had more than one year of experience participated in the study. Data collected by pretested structured questionnaire and data analysis was done using SPSS 20v and summarized by descriptive statistics. Proportion and Chi-square was calculated at $5 \% \alpha$. The result showed that among 862 HCPs who work outside the operation theatre and ICUs, appropriate uses of PPE were only 156 (18.1\%). The reasons for inappropriate use of PPE were 'non-available' 562 (78\%) followed by 'not aware of the importance' 77 (11\%). Findings of the study concluded that inappropriate use and lack of adequate knowledge on infection control practices emphasizing that periodic re-training is needed. ${ }^{6}$

An article published by Sarah Chapman, on Personal 
Protective Equipment (PPE) to protect Healthcare Workers (HCW): new Cochrane evidence, i.e. Personal protective equipment for preventing highly infectious diseases due to exposure to contaminated body fluids in healthcare staff and, Barriers and facilitators to healthcare workers' adherence with Infection Prevention and Control (IPC) guidelines for respiratory infectious diseases: a rapid qualitative evidence synthesis, supports the need of our study by explaining the importance on understanding a range of factors about PPE use and concluded that face to face training in PPE use may reduce errors more than folder-based training. ${ }^{7}$

\section{Conclusion}

The major conclusions drawn on the basis of the findings of the study were that, Majority of the samples had good knowledge but the maximum number of samples are following average practice of PPE.

Many implications were drawn out from the study like use of PPE in practice was not up to the mark for the student nurses dealing with the patients with Hepatitis, Tuberculosis like disease condition. In the Nursing curriculum, special emphasis should be given and during clinical teaching, it should be taken as a priority as taken for the nursing care. Many interventional studies should be taken place to check the effectiveness of learning and effect of demonstrations of these procedures of utilizing and discarding the PPE especially in the current scenario like COVID-19 pandemic So, this implies the need for improving and strictly following the standard practice. So, it is recommended that better strategies should be used to provide education to student nurses in classrooms and clinical teaching.

\section{Acknowledgment}

We would like to place on record the hard work and the tireless efforts in data collection and compilation of the thesis of B.Sc.(H) Nursing Students, Batch 2017-2021 of Rufaida College of Nursing, Jamia Hamdard, namely, Ms. Ansiya Dileep, Ms. Anupam Sisodia, Mr. Anush Joshua Chand, Ms. Babita C Babu, Ms. Dimple, Ms. Sayyada, Ms. Tenzin Kalssang, Mr. Ummer Rasool Dar.

\section{Conflict of Interest: None}

References

1. US Food and Drug Administration. Personal Protective equipment for infection control (document on the Internet). Updated 2020 February 02; cited 2020 February 19. Available from: https://www.fda.gov/ medical-devices/general-hospital-devices-andsupplies/personal-protective-equipment-infectioncontrol.

2. Wikipedia. Infection. Updated 2020 September 16; cited 2020 February 19. Available from: https://en.wikipedia.
org/wiki/Infection\#: :text=An\%20infection\%20is\%20 the $\% 20$ invasion,and\%20the\%20toxins\%20they\%20 produce.

3. World Health Organization. The burden of health careassociated infection worldwide. Cited 2020 February 19. Available from: https://www.who.int/gpsc/country_ work/burden_hcai/en/.

4. Chughtai AA, Khan W. Use of personal protective equipment to protect against respiratory infections in Pakistan: A systematic review. Published on: 2020 March 4; Updated on: 2020 March 13; cited on: 2020 March 5. Available from: https://www.ncbi.nlm.nih. gov/pmc/articles/PMC7102706/.

5. Universal Class. The History of Personal Protective Equipment. Cited on 2020 March 5. Available from: https://www.universalclass.com/articles/business/ the-history-of-personal-protective-equipment.html.

6. Lakshmi APA, Jennifer HG, Stanly AM. A study on personal protective equipment use among health care providers, Tamil Nadu. 2018. Cited on: 2020 March 7. Available from: https://www.ijcmph.com/index.php/ ijcmph/article/view/2894.

7. Chapman S. Personal protective equipment (PPE) for healthcare workers: new Cochrane evidence. Published on 2020 April 28; retrieved on 2020 September 11. Available from: https://www.evidentlycochrane.net/ personal-protective-equipment/. 